\title{
Prophylactic effect of Nigella sativa against lead acetate induced changes in spermiogram, reproductive hormones and gonadal histology of rats
}

\author{
Mohammed Abdulrazzaq Assi ${ }^{1,2}$, Mohammed Noor Mohd Hezmee ${ }^{2}$, Yusuf Abba ${ }^{3}$, Md Sabri Md Yusof ${ }^{3}$, Abd Wahid Haron ${ }^{4}$, \\ Mohamed Ali Rajion² and Mashaan Abbas Al-Zuhairy ${ }^{5}$
}

\begin{abstract}
1. Department of Community Health, College of Health and Medical Techniques, Al-Furat Al-Awsat Technical University, Iraq; 2. Department of Veterinary Preclinical Sciences, Faculty of Veterinary Medicine, Universiti Putra Malaysia, 43400 , Serdang, Selangor, Malaysia; 3. Department of Veterinary Pathology and Microbiology, Faculty of Veterinary Medicine, Universiti Putra Malaysia, 43400 Serdang, Selangor, Malaysia; 4. Department of Veterinary Clinical Studies, Faculty of Veterinary Medicine, Universiti Putra Malaysia, 43400 Serdang, Selangor, Malaysia; 5. Department of Veterinary Public Health, College of Veterinary Medicine, Baghdad University, Iraq.

Corresponding author: Mohammed Noor Mohd Hezmee, e-mail: hezmee@upm.edu.my,

MAA: razaq_assi@yahoo.com, YA: yabbavet@gmail.com, MSMY: mdsabri@upm.edu.my, AWH: wahidh@upm.edu.my, MAR: marajion@gmail.com, MAAZ: mashaanaz@yahoo.com

Received: 08-07-2016, Accepted: 24-10-2016, Published online: 27-11-2016
\end{abstract}

doi: 10.14202/vetworld.2016.1305-1311 How to cite this article: Assi MA, Hezmee MNM, Abba Y, Md. Yusoff MS, Haron AW, Rajion MA, Al-Zuhairy MA (2016) Prophylactic effect of Nigella sativa against lead acetate induced changes in spermiogram, reproductive hormones and gonadal histology of rats, Veterinary World, 9(11): 1305-1311.

\begin{abstract}
Aim: This study was designed to evaluate the prophylactic effect of Nigella sativa (NS) treatment on toxic effects induced by lead acetate (LA) on the reproductive hormones, spermiogram and gonadal histology of rats.

Materials and Methods: A total of 20 Sprague-Dawley rats were divided into four groups of five rats each. Group 1 (negative control $[\mathrm{NC}]$ ) was the $\mathrm{NC}$ and was given distilled water, Group 2 served as the positive control (PC) and was administered $10 \mathrm{mg} / \mathrm{kg} /$ day of LA per overall survival (OS), Group 3 (T1) was administered $200 \mathrm{mg} / \mathrm{kg} / \mathrm{daily}$ of NS per OS for a month, and Group 4 (T2) was pretreated with $200 \mathrm{mg} / \mathrm{kg} /$ daily of NS per OS for 1 month, followed by $10 \mathrm{mg} / \mathrm{kg} / \mathrm{daily}$ of LA alone per OS for another. The rats were euthanized at the end of the experimental period for collection of blood and the right caudal epididymis and testis. Serum was used for determination of reproductive hormones by using radioimmunoassay kits. The epididymal segment was cut and homogenized in phosphate-buffered saline, and the homogenate was used for determination of the spermiogram parameters such as sperm concentration, sperm viability, percentage of live sperm, motility and abnormality. Both the epididymis and testis were fixed in $10 \%$ buffered formalin for histological processing.

Results: The sperm concentration, general, and individual motilities were higher $(\mathrm{p}<0.05)$ in the NC and T1 animals, while the T2 had intermediate and the PC had lower $(\mathrm{p}<0.05)$ values of each parameter. The percentage sperm viability was higher $(\mathrm{p}<0.05)$ in the T1 and lower $(\mathrm{p}<0.05)$ in the PC group. However, percentage abnormality was lower in T1, comparable in $\mathrm{NC}$ and $\mathrm{T} 2$, and higher $(\mathrm{p}<0.05)$ in PC. Spermatogenic cell population and epididymal sperm reserve (ESR) were optimal in control and pretreated animals, while the PC had lower spermatids and ESR. The concentration of estradiol (EST) was lower $(\mathrm{p}<0.05)$ in the PC and T2, while leuteinizing hormone $(\mathrm{LH})$ concentration was lower $(\mathrm{p}<0.05)$ in the $\mathrm{PC}$, and comparable $(\mathrm{p}>0.05)$ between control and T2. The concentration of follicle-stimulating hormone ( $\mathrm{FSH})$ was comparable $(\mathrm{p}>0.05)$ in all groups, while testosterone (TS) hormone concentration was lower $(\mathrm{p}<0.05)$ in the PC and higher in the control and T1 groups.
\end{abstract}

Conclusion: This study showed the preventive effects of NS administration against alterations in reproductive hormnes, sperm parameters and gonadal histology caused by LA in rats.

Keywords: histology, lead acetate, infertility, Nigella sativa, spermiogram, toxicity.

\section{Introduction}

Lead is considered as one of the most hazardous and cumulative environmental pollutants that affect all biological systems through exposure from air, water, and food sources [1]. The effects of lead on tissues and organs have been attributed to the excessive generation of reactive oxygen species (ROS), an issue that

Copyright: Assi, et al. Open Access. This article is distributed under the terms of the Creative Commons Attribution 4.0 International License (http://creativecommons.org/licenses/by/4.0/), which permits unrestricted use, distribution, and reproduction in any medium, provided you give appropriate credit to the original author(s) and the source, provide a link to the Creative Commons license, and indicate if changes were made. The Creative Commons Public Domain Dedication waiver (http://creativecommons.org/ publicdomain/zero/1.0/) applies to the data made available in this article, unless otherwise stated. was recently given much attention. Sulfhydryl antioxidant production is inhibited by ROS, which damages nucleic acids, inhibits the repair of DNA and inhibits reactions of enzyme, thus enhancing peroxidation of lipids in cellular membranes [2,3]. Lead induced oxidative stress promotes hydrogen peroxide $\left(\mathrm{H}_{2} \mathrm{O}_{2}\right)$ generation [4]. Lead acetate (LA) has been shown to decrease male reproductive organ function by causing testicular tissue alterations in the histological patterns of the testis [5].

Nigella sativa Linn. (NS) is an annual herb that belongs to the family Ranunculaceae and is most extensively investigated for its therapeutic purposes [6,7]. Both the seed and oil of NS have been shown to exhibit different therapeutic properties 
which include antiparasitic, antifungal, anticancer, antimicrobial, anti-inflammatory, and effects against toxicity $[8,9]$. The ameliorative effects of NS against sodium valproate [10], heat stress [11], LA [12], isoproterenol [13], tramadol [14], and cisplatin toxicity [15] have been reported in literature.

NS oil was shown to counteract the impairment in epididymal sperm characteristics caused by $\mathrm{H}_{2} \mathrm{O}_{2}$ exposure [16]. Similarly, both the oil and seed of NS have been shown to increase sperm production, semen quality, sperm count, and volume of semen, seminiferous tubular diameter, increased sperm motility and percentage fertility, decreased sperm abnormality index as well as increased hormonal levels [17]. The administration of LA to male rats have also been reported to affect the levels of reproductive hormones; testosterone (TS), estrogen and luteinizing hormone $(\mathrm{LH})$ as well as reduce sperm viability, motility, concentration, gonadal weight and increase sperm abnormalities, and degenerative and necrotic conditions in the testis [5,18-20].

NS is a popular folkloric medicinal plant whose seeds, leaves and oil have been used to treat various sicknesses for centuries. The seed and oil of NS have been reported to be safe with a high safety margin following oral intake. NS have been reported to exhibit potent anti-inflammatory, analgesic, anticarcinogenic, antidiabetic, antiulcer, antimicrobial, and antiparasitic activities $[9,21]$. In related studies, both administrations of NS seed and oil have been found to improve sperm counts, sperm viability and motility, testicular weights, decrease sperm abnormalities, and testosterone concentration $[10,17,22]$. Similarly, increased levels of reproductive hormones were observed after administration of NS oil in male rats [23].

Since most of these studies used NS as a therapeutic rather than a prophylactic regiment, this study was hence designed to evaluate the prophylactic effect of NS pretreatment on LA administration with emphasis on sperm production index, reproductive hormonal levels and histology of the testis and epididymis of rats.

\section{Materials and Methods}

\section{Ethical approval}

The animal experimental protocol used in this study was approved by the Institutional Animal Care and Use Committee (IACUC) with reference number: UPM/IACUC/AUP-R047/2015, in accordance with the standard guidelines on usage and care of laboratory animals.

\section{Preparation of NS and LA solutions}

Black seeds (NS) were obtained, cleaned, and grounded using an electric grinder (National Blender 8011S, Model HGB2WTS3, USA) for $10 \mathrm{~min}$ to get water-soluble powder. A suspension of $10 \mathrm{~g} / \mathrm{L}$ of the powder was prepared for this experiment. LA (Oxford Lab., Co., India) was dissolved in distilled water at a concentration of $10 \mathrm{mg} / \mathrm{kg}$ body weight (BW) and administered to the rats via a gavage tube.

\section{Animal grouping and treatment}

About 20 adult male rats were randomly divided into four groups of five animals each. Hygienic condition was maintained by changing the bedding weekly. The animals were kept for 15 days for acclimatization before commencement of the experiment.

Group I negative control (NC) was given distilled water, orally. Group II (LA treated group) (positive control [PC]) was given $10 \mathrm{mg} / \mathrm{kg}$ of LA, orally for 30 days [24,25]. Group III (NS treated group) was given $200 \mathrm{mg} / \mathrm{kg}$ BW of NS water suspension, orally for 30 days [26,27], while Group IV (NS followed by LA treated group) was pre-treated with NS $200 \mathrm{mg} / \mathrm{kg}$ $\mathrm{BW}$, orally for 30 days [13], followed by LA $10 \mathrm{mg} / \mathrm{kg}$ BW daily for another 30 days $[24,25]$.

Sperm counts (sperm concentration, viability, individual motility, general motility, and abnormality)

The right caudal epididymis was immediately placed in $2 \mathrm{~mL}$ of phosphate-buffered saline and cut into about 200 pieces using a surgical micro-scissor to release the spermatozoa from the epididymal tubules. Epididymal semen suspension (ESS) was immediately incubated at $37^{\circ} \mathrm{C}$ for further examination. $10 \mu \mathrm{l}$ of ESS was added to $190 \mu \mathrm{l}$ of formal saline, to make a dilution factor of 1:20. The total sperm concentration was determined using a Neubauer hemocytometer as described previously by Yokoi et al. [28]. To evaluate the mass motility, $5 \mu \mathrm{l}$ of the suspension was put on a glass slide and examined under a phase-contrast microscope at a magnification of $100 \times$. Mass motility was graded using the percentage motility of the spermatozoa. Moreover, general motility was evaluated by taking $10 \mu 1$ of ESS on glass slide, covered with cover slip and examined under phase-contrast microscope at $400 \times$ magnification. Eosin-nigrosin stain was used to stained the sperm to determine its viability and morphology.

\section{Processing of tissue samples for histopathology}

Tissue samples of the testis and epididymis were collected in $10 \%$ neutral buffered formalin and fixed for $48 \mathrm{~h}$. Formalin-fixed tissues sections were processed through serial dehydration in ethanol, embedded in paraffin wax, sectioned at 5-6 $\mu \mathrm{m}$ and stained with hematoxylin and eosin for histopathological examination of each animal through light microscopy at $200 \times$ and $400 \times$ magnification. Photomicrographs of microscopic focal fields were taken using Miotic ${ }^{\circledR}$ microscope

\section{Radioimmunoassay for follicle stimulating hor- mone (FSH), LH, estradiol (ESR) and testosterone measurements}

Beckman Coulter Immunotech Radioimm unoassay kits were used for the plasma determination of $\mathrm{FSH}, \mathrm{LH}$, estradiol and testosterone concentrations as previously described [29]. Briefly, $50 \mu 1$ of the calibrator and plasma from different groups were added to $500 \mu \mathrm{l}$ of tracer in an anti-LH or anti-FSH or anti-estradiol antibody-coated tubes, mixed and incubated at $18-25^{\circ} \mathrm{C}$ in a shaker set at $350 \mathrm{rpm}$. Wallac Wizard Gamma Counter model 1470 was used to determine 
the counts per minute (cpm) of the solution. For the evaluation of testosterone concentration, $200 \mu 1$ of the plasma was mixed $2 \mathrm{ml}$ of ethyl ether and vortexed vigorously for $1 \mathrm{~min}$. The mixture was kept at $-18^{\circ} \mathrm{C}$ until a frozen aqueous phase was achieved. The aqueous phase was separately collected and in a water bath at $37^{\circ} \mathrm{C}$ until evaporation. The resultant dry ether extract was re-dissolved in $200 \mu \mathrm{l}$ of recovery buffer, vortexed vigorously, and mixed in tracer antibody-coated tubes. The tubes were incubated at $37^{\circ} \mathrm{C}$ water bath for $1 \mathrm{~h}$, and the solution was used for determination of total cpm using Wallac Wizard Gamma Counter model 1470 [29].

\section{Statistical analysis}

Data obtained from the spermiogram was summarized as mean \pm standard error and analyzed with Graph Pad Prism 6.0 using one-way analysis of variance with Tukey multiple comparison post-hoc test. A value of $p<0.05$ was considered significant.

\section{Results}

\section{Changes in spermiogram parameters}

In this study, it was observed that LA had a deleterious effect on the spermiogram of rats. Consequently, prior administration of NS was able to prevent the development of such effects. Sperm concentration and individual motility were both higher $(\mathrm{p}<0.05)$ and comparable in the $\mathrm{NC}$ and $\mathrm{T} 1$ groups, while the $\mathrm{PC}$ had a lower $(p<0.05)$ value compared to all groups (Figure-1a and c). The percentage viability was different $(p<0.05)$ in all groups, with the T1 having a higher value and the $\mathrm{PC}$ with a lower value (Figure-1b). The general motility was higher $(\mathrm{p}<0.05)$ and comparable in the NC and T1 groups; however, there is no difference $(p>0.05)$ between the T1 and T2, while the PC had a lower $(p<0.05)$ general motility (Figure-1d). The percentage abnormality was higher $(p<0.05)$ in the PC and comparable $(\mathrm{p}>0.05)$ between $\mathrm{NC}$ and $\mathrm{T} 2$, and T1 and T2 (Figure-1e).

\section{Histological findings}

Optimal spermatogenesis was seen in the testis of NC and T1 animals. The PC group had vacuolations within the seminiferous tubules, as well as low distribution of spermatogenic cells. In the T2 group, spermatogenesis was optimal in some tubules $(70 \%)$ and moderate in others (30\%). Tubules with moderate spermatogenesis had low distribution of spermatogenic cells. The distribution of sertoli cells and

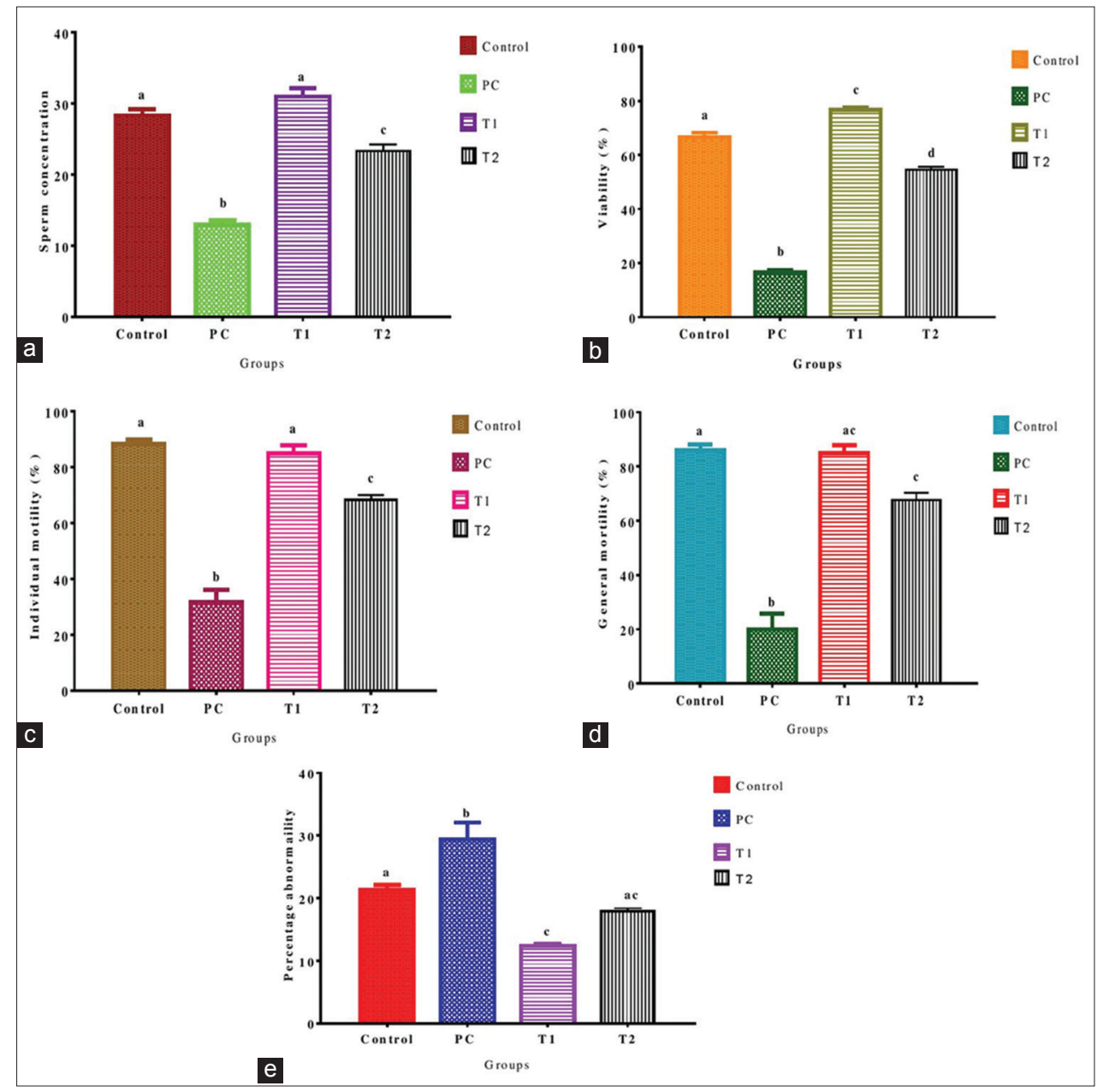

Figure-1: Sperm concentration (a) percentage viability, (b) individual motility, (c) general motility, (d) percentage abnormality, (e) in different experimental groups. a,b,c,d Bars with different superscript indicate statistical significance at $\mathrm{p}<0.05$. 
spermatogonia was not different among all groups (Figure-2).

The epididymal sperm reserve (ESR) is an estimate of the epididymal tail luminal filling with spermatozoa. It indicates the state of sperm production as either optimal $(80-100 \%)$, moderate $(>50 \%)$, or low $(<50 \%)$. The NC, T1 and T2 had optimal sperm reserves within the tail of the epididymis. However, the distribution of sperm cells was dense in the T1 group when compared to other groups, as evidenced by wave like pattern. The PC group had a reduced ESR depicted by moderate distribution of sperm cells in the epididymal tail (Figure-3).

\section{Reproductive hormonal concentrations}

There was no significant difference in the concentration of FSH in all groups. However, the concentration of LH was significantly lower in the PC group, while the T1 group had a higher value that was elevated above the control and T2 groups. The concentration of TS was significantly lower in the PC once compared with other groups. Similarly, EST concentration was also lower in the PC and T2 groups and higher in the control and T1 groups (Figure-4).

\section{Discussion}

In this study, we used the NS seeds to evaluate its ameliorative effects against the toxicity of LA. The results showed that NS had a protective effect in the reproductive organs after the inducement of LA toxicity. However, the optimal dose of NS at $200 \mathrm{mg} / \mathrm{kg}$ $\mathrm{BW}$ reduced the harmful effects that LA caused in these organs.

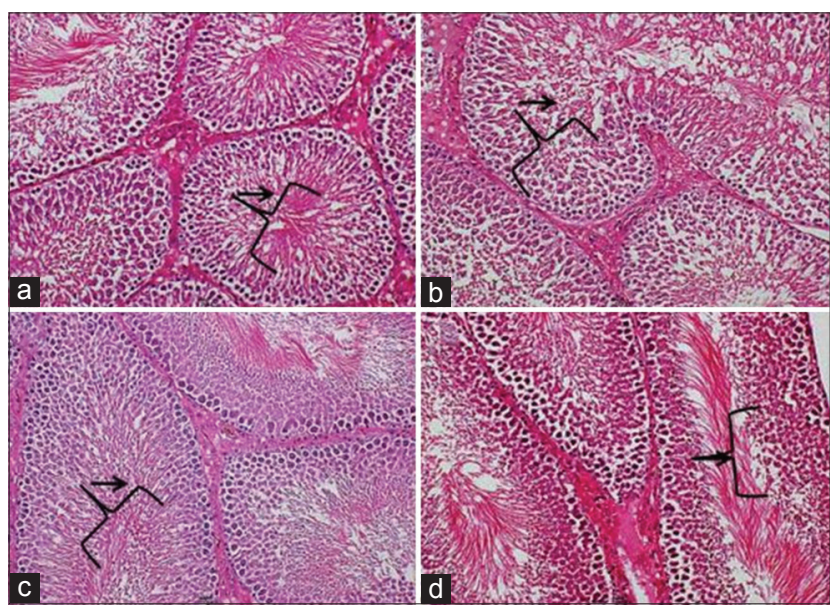

Figure-2: Photomicrograph section of the testis of rats from (a) control group, showing normal spermatogenesis characterized by different spermatogenic cells within the lumen of the seminiferous tubules (arrow), (b) positive control group, showing spermatogenic cells and evidence of spermatogenesis depicted by reduced number of sperm maturation stages in the seminiferous tubular lumen (arrow), (c) T1 group, showing optimal spermatogenesis with presence of all sperm maturation stages (arrow), (d) T2 group, showing normal distribution of spermatogenic cells with the seminiferous tubules (arrow) ( $H$ and $E$, $200 \times)$.
There are widely documented deleterious effects of LA on the developing and mature male reproductive organs and fertility in previous studies. Lead is known to induce malfunctioning of the reproductive organs by directly affecting its morphological structure, thereby also causing decreased sperm quality [30,31]. The ameliorative effects of NS against several toxic compounds have been reported in literature [10,13-15,32]. Al-Masri [33] had reported that LA caused significant decreases in sperm motility, count and viability of sperm, while there was in an increase in sperm abnormality. Similarly, Chowdhury [34] also reported the toxicity of lead in the male reproductive system by inducing alterations in sperm morphology, count, motility as well as a decrease in the male sexual hormones. Since the major function of testes is spermatogenesis and hormone production, damage to the testicular tissue by the toxic effects of lead impairs both the spermatogenic process and hormone production $[35,36]$. However, several studies in other rat strains and other rodents indicate fairly consistently that blood $\mathrm{Pb}$ concentrations $>30-40 \mu \mathrm{g} / \mathrm{dL}$ during at least 30 days of administration was associated with impairment of spermatogenesis and reduced concentrations of circulating androgens. This concurs with the findings of this study where it was observed that the LA (PC) group had reduced fertility index (sperm concentration, percentage viability, individual motility, general motility) and increased percentage abnormality when compared with the NS pre-treatment and control groups. Similarly, the PC group had less number of spermatids and vacuolations in the seminiferous tubule with reduced ESRs.

In a related study, a significant increase in the wall thickness of testicular seminiferous tubules was

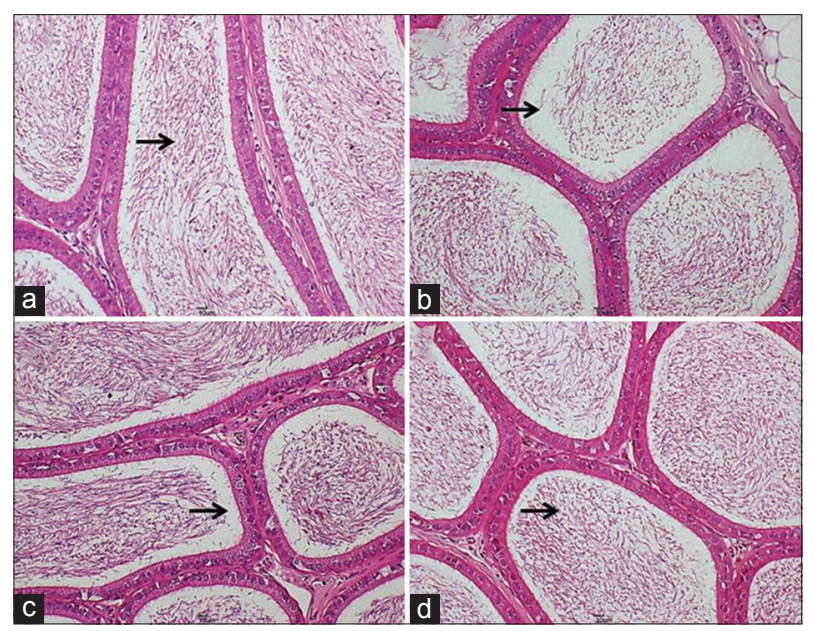

Figure-3: Photomicrograph section of the epididymal tail from (a) Control group, showing optimal epididymal sperm reserve (ESR) of $80-90 \%$ (black arrow), (b) positive control group, showing reduced ESR of $60-70 \%$ with sparse distribution of sperms (black arrow), (c) T1 group, showing marked distribution of sperms appearing as dense fibers within the lumen (black arrow), (d) T2 group, showing good ESR with moderate sperms distribution (black arrow) ( $\mathrm{H}$ and $\mathrm{E}, 200 \times$ ). 

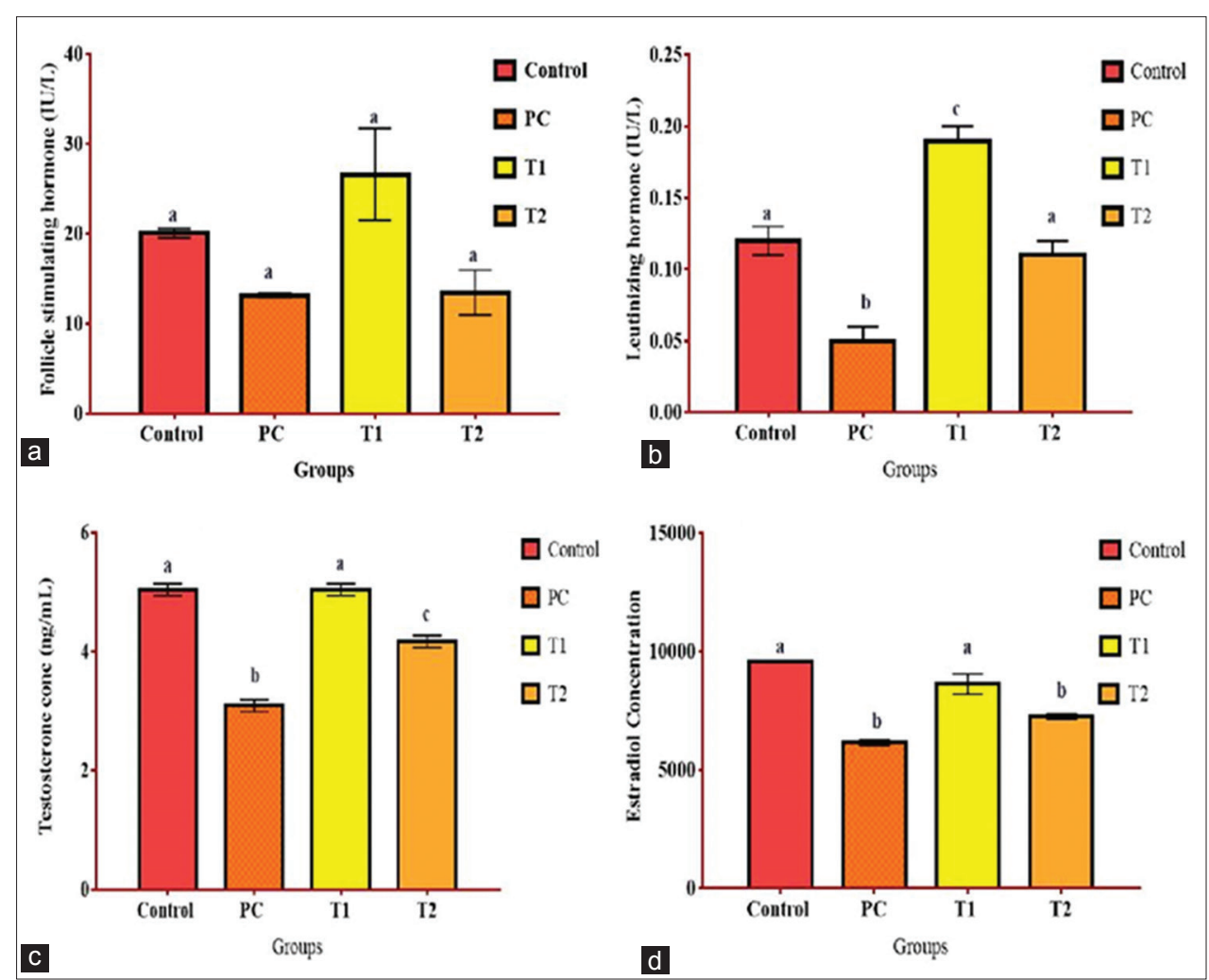

Figure-4: Reproductive hormonal concentration showing the difference in (a) Follicle-stimulating hormone (b), luteinizing hormone, (c) testosterone hormone and (d) estradiol in rats following pretreatment with Nigella sativa and lead acetate exposure. $a, b, c$ Bars with different superscript indicate statistical significance at $p<0.05$.

observed in mice administered $0.3 \mathrm{~mL}$ of the crude oil of NS [37]. Significant increases in BW gain, reproductive parameters (seminiferous tubules thickness and diameters, account of spermatogonia, primary and secondary spermatocytes, spermatids, free spermatozoa, account of Sertoli and Leydig cells, diameter of Leydig cells and the height of epithelial cells entirely covered epididymal caudal) and hormones (testosterone and FSH) were observed with treatment of alcoholic extract of black seed [38]. In this study, NS pretreatment was observed to significantly improve the fertility indexes by improving sperm concentration, percentage viability, individual motility, general motility and decreasing percentage abnormality. Furthermore, there was enhanced spermatogenesis and ESRs in pre-treated rats exposed to LA.

Furthermore, the administration of different doses of LA was shown to cause reduced testicular weight, sperm concentration and motility, increased sperm abnormalities and increased testicular degenerative changes in previous studies by Elgawish and Abdelrazek [5], Makhlouf et al. [18], and Allouche et al. [19]. Although there are numerous reported literatures on the ameliorative effect of NS oil against toxic injuries to the male reproductive organs and hormonal level decreases induced by other compounds $[10,11,15]$, there appears to be very little information on the effect of both its oil and seeds on LA induced testicular injuries and hormonal deficits in male animals.
The administration of NS to normal rats has been shown to boost the sperm production profiles and TS levels, indicating that the compound enhances male fertility $[17,23]$. In this study, LA reduced the concentration of sperm at the maturation stage in the testis and reduced tail ESRs indicating suppression of spermatogenesis, however, rats treated with graded doses of NS showed remarkable improvements in both spermatogenesis and ESRs. It is, therefore, obvious that NS prevented testicular tissue damage and even enhanced sperm production at $200 \mathrm{mg} / \mathrm{kg}$.

The reproductive hormones TS, EST and LH are important component of male sexual development and fertility. A significant decline in TS or an increase in EST and LH have been shown to adversely affect sexual maturity and fertility in male animals [39]. In this study, decreases in estradiol were observed in the PC and $\mathrm{T} 2$ groups on days 30 and 60 , respectively, while LH was decreased in PC and comparable between control and T2. The FSH concentration was comparable in all group. This showed deleterious effects of LA on the PC group and suppression of FSH production in the high dose treatment group (NS $200 \mathrm{mg} / \mathrm{kg}$ ). The decline in the level of TS in the PC in comparison to the the control and $\mathrm{T} 1$ groups can be attributed to the lesions observed at histopathology; this ultimately resulted in low sperm in both maturation stage and epididymal reserves which were translated into low sperm concentration and viability. Based on our recent study investigating the therapeutic effect of 
NS treatment against chronic LA induced toxicity, we observed that concurrent administration of graded doses of NS with LA for 90 days resulted in amelioration of the toxic effects of LA on the gonadal histology, spermiogram, reproductive hormones and oxidative stress enzymes. The study concluded that NS especially at a dose of $200 \mathrm{mg} / \mathrm{kg} \mathrm{BW}$ had enhanced therapeutic effects against chronic LA induced toxicity in rats [40].

The administration of NS oil to normal male rats was reported to increase the levels of TS, LH and FSH after 30-60 days, indicating a positive effect on the hormonal production $[17,22,23]$. Based on these reports, we can say that the NS seed powder played a therapeutic role on the testicular tissue and Leydig cells, hence maintaining TS production at normal levels throughout the experimental course. This agrees with a previous study, where NS oil at $250 \mathrm{mg} / \mathrm{kg}$ was reported to increase the level of TS in rats exposed to sodium valproate [10].

\section{Conclusion}

This study has shown the promising effect of NS pre-treatment in LA toxicity in male rats. The results showed enhanced fertility indexes in NS pre-treated rats, thus showing the important role of NS in preventing infertility in male rats exposed to LA.

\section{Authors' Contributions}

All authors mentioned have made substantial contribution to this manuscript and approved the list of authors in this manuscript. The authors: MAA, MNMH, YA, MSMY, AWH, MAR and MAAZ participated in the conception and design. MAA drafted the manuscript, while MHMN, YA, MSMY, AWH, MAR and MAAZ each critically revised and contributed to the intellectual content, and also editing of the paper. They all approved the final draft for submission and the list of authors.

\section{Acknowledgments}

The authors would like to acknowledge the receipt of funding from the Ministry of Higher Education, Malaysia through its Fundamental Research Grant scheme (5524282) used as financial support for this research.

\section{Competing Interests} interests.

The authors declare that they have no competing

\section{References}

1. Patra, R.C., Rautray, A.K. and Swarup, D. (2011) Oxidative stress in lead and cadmium toxicity and its amelioration. $J$. Vet. Intern. Med., 2011: 457327.

2. Salem, M.L. (2005) Immunomodulatory and therapeutic properties of the Nigella sativa L. Seed. Int. Immunopharmacol., 5(13): 1749-1770.

3. Assi, M.A., Hezmee, M.N.M., Haron, A.W., Sabri, M.Y. and Rajion, M.A. (2016a) The detrimental effects of lead on human and animal health. Vet. World, 9(6): 660-671.
4. Vaziri, N.D. and Khan, M. (2007) Interplay of reactive oxygen species and nitric oxide in the pathogenesis of experimental lead-induced hypertension. Clin. Exp. Pharmacol. Physiol., 34(9): 920-925.

5. Elgawish, R.A.R. and Abdelrazek, H.M. (2014) Effects of lead acetate on testicular function and caspase-3 expression with respect to the protective effect of cinnamon in albino rats. Toxicol. Rep., 1: 795-801.

6. Aggarwal, B.B., Kunnumakkara, A.B., Harikumar, K.B., Tharakan, S.T., Sung, B. and Anand, P. (2008) Potential of spice-derived phytochemicals for cancer prevention. Plant Med., 74(13): 1560-1569.

7. Kamal, A., Arif, J.M. and Ahmad, I.Z. (2010) Potential of Nigella sativa L. Seed during different phases of germination on inhibition of bacterial growth. J. Biotechnol. Pharm. Res., 1(1): 9-13.

8. Ahmad, A., Husain, A., Mujeeb, M., Khan, S.A., Najmi, A.K., Siddique, N.A. and Anwar, F. (2013) A review on therapeutic potential of Nigella sativa: A miracle herb. Asian Pac. J. Trop. Biomed., 3(5): 337-352.

9. Gali-Muhtasib, H., El-Najjar, N. and Schneider-Stock, R. (2006) The medicinal potential of black seed (Nigella sativa) and its components. Adv. Phytomed., 2: 133-153.

10. Hala, M.A. (2011) Protective effect of Nigella sativa, linseed and celery oils against testicular toxicity induced by sodium valproate in male rats. $J$. Am. Sci., 7(5): 687-693.

11. Al-Zahrani, S., Mohany, M., Saleh, K. and Badr, G. (2012) Thymoquinone and vitamin E supplementation improve the reproductive characteristics of heat stressed male mice. $J$. Med. Plant Res., 6(3): 493-499.

12. Farrag, A.R., Mahdy, K.A., Abdel, R.G. and Osfor, M.M. (2007) Protective effect of Nigella sativa seeds against lead-induced hepatorenal damage in male rats. Pak. J. Biol. Sci., 10(17): 2809-2816.

13. Murugesan, M., Ragunath, M., Prabu, T., Nadanasabapathi, S., Sakthivel, M. and Manju, V. (2012) Protective role of black cumin (Nigella sativa) on isoproterenol induced myocardial infarction in rats. Int. J. Pharm. Clin. Sci., 1: 45-53.

14. Elkhateeb, A., El Khishin, I., Megahed, O. and Mazen, F. (2015) Effect of Nigella sativa Linn oil on tramadol-induced hepato-and nephrotoxicity in adult male albino rats. Toxicol. Rep., 2: 512-519.

15. Awadalla, E.A. (2012) Ameliorative effect of the crude oil of the Nigella sativa on oxidative stress induced in rat testes by cisplatin treatment. Biomed. Prev. Nutr., 2(4): 265-268.

16. Tawfeek, F.K., Ahmed, S.M. and Kakel, S.J. (2006) Effect of Nigella sativa oil treatment on the sex organs and sperm characters in rats exposed to hydrogen peroxide. Mesopotamia J. Agric., 34(1): 2-8.

17. Mahdavi, R., Heshmati, J. and Namazi, N. (2015) Effects of black seeds (Nigella sativa) on male infertility: A systematic review. J. Herb. Med., 5(3): 133-139.

18. Makhlouf, M., Eldien, H., Zagloul, D., Dief, E.A. and AbdElhaliem, N. (2008) The effect of the lead acetateon testicular structure and protective effect of vitamin $\mathrm{E}$ in adult albino rat. Egypt. J. Histol., 31: 406-418.

19. Allouche, L., Hamadouche, M. and Touabti, A. (2009) Chronic effects of low lead levels on sperm quality, gonadotropins and testosterone in albino rats. Exp. Toxicol. Pathol., 61(5): 503-510.

20. El-Tohamy, M. and El-Nattat, W. (2010) Effect of antioxidant on lead-induced oxidative damage and reproductive dysfunction in male rabbits. J. Am. Sci., 6(11): 613-622.

21. Ali, B.H. and Blunden, G. (2003) Pharmacological and toxicological properties of Nigella sativa. Phytother. Res., 17(4): 299-305.

22. Bashandy, A.S. (2007) Effect of fixed oil of Nigella sativa on male fertility in normal and hyperlipidemic rats. Int. J. Pharmacol., 3(1): 27-33.

23. Juma, F.T. and Hayfaa, M. (2011) A: The effects of Nigella sativa oil administration on some physiological and 
histological values of reproductive aspects of rats. Iraqi $J$. Vet. Med., 35: 52-60.

24. Arrak, J.K., Al-Khafaji, N.J. and Hassan, A.A. (2012) Effect of date palm pollen suspension on ovarian function and fertility in adult female rats exposed to lead acetate. Diyala $J$. Med., 3(1): 90-96.

25. Mustafa, H.N. and Hussein, A.M. (2015) Does allicin combined with vitamin B-complex have superior potentials than $\alpha$-tocopherol alone in ameliorating lead acetate-induced Purkinje cell alterations in rats? An immunohistochemical and ultrastructural study. Folia Morphol. (Praha), 75(1): 1-17.

26. Yoruk, O., Gur, F., Uyanik, H., Yasar, M., Mutlu, V., Altas, E. and Taysi, S. (2010) Antioxidant effects of Nigella sativa in the treatment of experimentally induced rhinosinusitis. Maced. J. Med. Sci., 3(2): 132-137.

27. Jahromy, M.H., Jalili, M., Mohajer, A.J., Poor, F.K. and Dara, S.M. (2014) Effects of Nigella sativa seed extract on perphenzine-induced muscle rigidity in male mice. World $J$. Neurosci., 4: 313-318.

28. Yokoi, K., Uthus, E.O. and Nielsen, F.H. (2003) Nickel deficiency diminishes sperm quantity and movement in rats. Biol. Trace Elem. Res., 93(1-3): 141-153.

29. Jesse, F.F.A., Abba, Y., Tijjani, A., Sadiq M.A., Konto, M., Adamu, L., Wahid, A.H., MohdAzmi, M.L., Eric, L.T.C. and Ab Rahman, M.F. (2016) Gonado-hypophyseal lesions and reproductive hormonal changes in brucella melitensis-infected mice and its lipopolysaccharides (lpss). Comp. Clin. Pathol., 25: 31-36.

30. Dorostghoal, M., Dezfoolian, A. and Sorooshnia, F. (2011) Effects of maternal lead acetate exposure during lactation on postnatal development of testis in off spring wistar rats. Iran. J. Basic Med. Sci., 14: 122-131.

31. Sharma, R. and Garu, U. (2011) Effects of lead toxicity on developing testes in swiss mice. Univ. J. Environ. Res. Technol., 1: 390-398.

32. Krishnan, N. and Muthukrishnan, S. (2012) Effect of Nigella sativa seed extract on carbon tetrachloride-induced hepatotoxicity in rats. Acute Med., 2(4): 107-113.

33. Al-Masri, S.A. (2015) Effect of pumpkin oil and vitamin E on lead induced testicular toxicity in male rats. J. Anim. Plant Sci., 25(1): 72-77.

34. Chowdhury, A.R. (2009) Recent advances in heavy metals induced effect on male reproductive function - A retrospective. Al Ameen J. Med. Sci., 2(2): 37-42.

35. Brennan, J. and Capel, B. (2004) One tissue, two fates: Molecular genetic events that underlie testis versus ovary development. Nat. Rev. Genet., 5(7): 509-521.

36. García-Lestón, J., Méndez, J., Pásaro, E. and Laffon, B. (2010) Genotoxic effects of lead: An updated review. Environ. Int., 36(6): 623-636.

37. Al-Zuhairy, R.G.M. (2012) The phototherapeutic effect of traditional crude oil of Nigella sativa on male reproductive system of albino mice treated with low toxic dose of paracetamol. Iraqi Acad. Sci. J., 9(1): 229-237.

38. Al-Sa'aidi, J.A.A., Al-Khuzai, A.L.D. and Al-Zobaydi, N.F.H. (2009) Effect of alcoholic extract of Nigella sativa on fertility in male rats. Iraqi J. Vet. Sci., 23 Suppl II: 123-128.

39. Mann, T. and Lutwak-Mann, C. (2012) Male Reproductive Function and Semen: Themes and Trends in Physiology, Biochemistry and Investigative Andrology. Springer Science \& Business Media, Berlin.

40. Assi, M.A., Hezmee, M.N.M., Abba, Y., Rajion, M.A., Wahid, H. and Yusof, M.S.M., (2016b). Assessment of therapeutic effects of Nigella sativa against chronic lead acetate-induced reproductive dysfunction in male SpragueDawley rats. Comp. Clin. Pathol., pp.1-11. 